\title{
Hominin raw material procurement in the Oldowan-Acheulean transition at Olduvai Gorge
}

Lindsay J. McHenry, ${ }^{\mathrm{a},}$ and Ignacio de la Torre ${ }^{\mathrm{b}}$

a Department of Geosciences, University of Wisconsin, Milwaukee, 3209 N. Maryland Ave., Milwaukee, WI 53211 USA

${ }^{\mathrm{b}}$ Institute of Archaeology, University College London, 31-34 Gordon Square, WC1H 0PY, London, United Kingdom.

${ }^{*}$ Corresponding author:

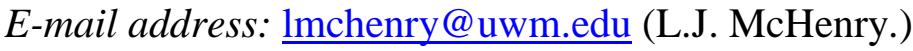

Keywords: Early Stone Age; Lower Pleistocene; lithic technology; early human procurement strategies; petrographic and geochemical analyses 


\begin{abstract}
The lithic assemblages at the Oldowan-Acheulean transition in Bed II of Olduvai Gorge, Tanzania, represent a wide variety of raw materials reflecting both the diversity of volcanic, metamorphic, and sedimentary source materials available in the Olduvai basin and surroundings and the preferences of the tool-makers. A geochemical and petrographic systematic analysis of lava-derived archaeological stone tools, combined with textural and mineralogical characterization of quartzite, chert, and other metamorphic and sedimentary raw materials from two Middle and Upper Bed II sites, has enabled us to produce a comprehensive dataset and characterization of the rocks employed by Olduvai hominins, which is used here to establish a referential framework for future studies on Early Stone Age raw material provenancing. The use of rounded blanks for most lava-derived artifacts demonstrates that hominins were accessing lava in local stream channels. Most quartzite artifacts appear to derive from angular blocks, likely acquired at the source (predominantly Naibor Soit hill), though some do appear to be manufactured from stream-transported quartzite blanks. Raw material composition of the EF-HR assemblage indicates that Acheulean hominins selected high-quality lavas for the production of Large Cutting Tools. On the other hand, the HWK EE lithic assemblage suggests that raw material selectivity was not entirely based on rock texture, and other factors, such as blank shape and availability of natural angles suitable for flaking, played a major role in Oldowan reduction sequences.
\end{abstract}




\section{Introduction}

The relative abundances and total mass of lithic artifacts made from different materials reflect both raw material availability and hominin preferences for specific materials. Potential raw material sources can be primary (e.g., in situ outcrops), secondary (e.g., cobbles from drainages derived from primary sources), or tertiary (e.g., hominin-made stone caches). This study will focus on primary and secondary sources at Olduvai Gorge. Hominins in the Olduvai Basin during Bed II times accessed and used a wide variety of raw materials from the local environment to manufacture stone tools. The Ngorongoro Volcanic Highlands to the east and south provide a variety of lava types, many of which would have been available to hominins in the Olduvai Basin as cobbles in stream channels draining the highlands (Leakey, 1971; Hay, 1976; Kyara, 1999). Precambrian metamorphic inselbergs (predominantly Naibor Soit and Naisiusiu) provide a local source for quartzite, and lacustrine chert nodules would have been intermittently exposed at the margins of the Olduvai paleolake (Hay, 1976).

Previous researchers have categorized Olduvai stone tools into general raw material groups (e.g., lavas, quartzite, and chert: Leakey, 1971; Kimura, 2002; or phonolite, basalt, trachyte, quartzite, and chert: Hay, 1976) and made inferences about raw material selection, availability, and transport based on the relative abundances of each, distance from source, and the proportion of flakes compared to cores (see also Kyara, 1999). Blumenschine et al. (2008, 2012) and Tactikos (2005) document changes in quartzite stone tool abundances with increasing distance from the presumed source (Naibor Soit), likely reflecting increased conservation of material with greater transport distances (distance-decay). In their studies, similar trends are not seen for lava-derived lithics, as flakeable stream cobbles would have been less geographically restricted. Other researchers (e.g., Stiles et al., 1974; Kimura, 1997) have focused on intervals in Bed II with exceptionally high abundances of chert artifacts, manufactured at a time when Olduvai lake-precipitated chert nodules would have been a readily available and desirable raw material source.

Four large Pliocene to Pleistocene volcanoes directly border the Olduvai Basin (Fig. 1), providing a potential primary source for lava raw materials for stone tool manufacture. To the south sits Lemagurut, a massive, heavily dissected volcano with basaltic to trachyandesitic lavas (2.40 \pm 0.01 to $2.22 \pm 0.10 \mathrm{Ma}$ : Mollel et al., 2011), and to the southeast sits the older and more eroded Satiman, with its silica undersaturated phonolites and phono-tephrites (4.63 \pm 0.05 to $4.02 \pm 0.02 \mathrm{Ma}$ : Mollel et al., 2011). To the east and southeast sits Ngorongoro, characterized by its rhyolitic tephra and ignimbrites (rarely if ever used as raw material for tools), along with lavas ranging from basalt to trachydacite $(2.25 \pm 0.02$ to $2.01 \pm 0.02$ Ma: Mollel et al., 2008). Olmoti, to the east, has basaltic through trachytic lavas $(2.01 \pm 0.03$ to $1.80 \pm 0.01 \mathrm{Ma}$ : Mollel et al., 2009). Engelosin, a small volcanic neck to the north of Olduvai, provides distinctively green and fine-grained phonolite (2.97 $\pm 0.02 \mathrm{Ma}$ : Mollel, 2007). All of these volcanic centers were present and had ceased eruption of new materials before the deposition of 
Bed II sediments (Mollel and Swisher, 2012), and all are positioned such that paleodrainages could have transported raw materials into the basin, making them locally available in stream channels during Bed II times. Such streams would have served as secondary sources for lava raw materials. Other Ngorongoro Volcanic Highlands (NVH) volcanoes are either too young or are blocked by the older volcanoes from supplying eroded lavas into the Olduvai basin. Mollel and Swisher (2012) provide a geochronological, geochemical, and petrological overview of likely NVH source volcanoes. Figure 2 provides a composite stratigraphic section for Olduvai Bed II, including previously published ages for some marker tephra.

Naibor Soit hill is a prominent metamorphic inselberg located just to the north of the Olduvai "junction" area (Fig. 3). Current exposures provide coarse grained quartzite, often weathering into angular slabs along planes with abundant muscovite mica. The hill is currently a major topographic high and would have been exposed throughout the deposition of the Olduvai beds, always available for hominin exploitation provided that it was not an island at times of extreme lake level for paleolake Olduvai. Naisiusiu hill is a smaller metamorphic inselberg just to the south of the Main Gorge at its far western extent (near the end of the Olduvai Basin deposits at Granite Falls). Its quartzite is finer grained and often darker in color, and visually distinct from quartzites from Naibor Soit. Other local metamorphic inselbergs (e.g., Kelogi) are more gneissic and do not provide quality materials for flaking (Hay, 1976).

Chert nodules formed within the sediments of paleolake Olduvai during specific intervals. They are scattered within the lacustrine claystones of Bed II near Hay's (1976) RHC locality (near the center of the paleolake) and form more concentrated layers above the level of Tuff IIA (Fig. 2), which are especially evident in the Olduvai Side Gorge (Hay, 1976). These chert nodules are typically small (rarely larger than $10 \mathrm{~cm}$ ) and would have been available for exploitation either in situ or following fluvial transport when these layers were eroded. Chert in the Side Gorge is especially abundant above a disconformity associated (by Stiles et al., 1974; and Hay, 1976) with the Lower Augitic Sandstone (LAS) in the Main Gorge. The MNK chert factory site, documented in detail by Stiles et al. (1974), includes a high concentration of chert artifacts at this level. It is likely that hominins took advantage of more accessible secondary sources for most raw materials, such as stream drainages that transported cobbles of lava from the adjacent volcanic highlands.

Studies involving various aspects of raw material characterization, sourcing, and the selectivity of Oldowan tool-makers have been conducted previously at Olduvai, other Pleistocene sites in eastern Africa, and elsewhere. Most studies make use of field observations and perhaps hand-lens examination of unbroken lithic artifacts (and potential source materials) for this characterization (e.g., Stout et al., 2005GoldmanNeuman and Hovers, 2009). However, cases where this approach leads to mischaracterization of the raw materials (even at the level of distinguishing igneous from sedimentary source rocks, e.g., Calogero, 1992; Hermes et al., 2001) show the advantages 
of petrographic and/or geochemical analysis for confirmation, especially for fine-grained material.

Petrographic and geochemical analysis can serve as a test for field raw material classifications. While time-consuming and destructive analysis (e.g., thin sectioning, sample powdering for geochemical study) is not appropriate for large collections of artifacts, the analysis of representative samples (from natural stream cobbles from associated conglomerates, where available) can help define compositional and textural groups. Such groups can be used to further subdivide lithic artifact collections based on raw material properties and ensure proper grouping based on field and non-destructive laboratory analysis. For example, Harmand (2009) and Goldman-Neuman and Hovers (2012) made use of thin section petrography in their characterizations of Oldowanassociated cobbles at Lokalalei (West Turkana) and Hadar, respectively, using the resulting mineralogical and textural data to further subdivide igneous raw materials and make inferences about hominin selectivity. Braun et al.'s (2008, 2009a, b, c) analyses of Kanjera and Koobi Fora Oldowan raw materials (artifacts, along with both primary and secondary raw material sources) relied on geochemistry, both destructive (ED-XRF of powdered and pressed samples) and non-destructive (ED-XRF of sample surfaces).

Following on these studies of early Pleistocene hominin raw material procurement patterns in eastern Africa, our aim is to present here a systematic analysis of rock types used by Olduvai hominins during the stratigraphic interval where the emergence of the Acheulean took place, at 1.7-1.4 Ma (McHenry et al., 2016). This transition occurred at Olduvai Gorge in the interval spanning the LAS and the Middle Augitic Sandstone (McHenry, submitted; Stanistreet et al., submitted), and over the last few years the Olduvai Geochronology Archaeology Project (OGAP) has investigated several paleoanthropological localities in Lower, Middle, and Upper Bed II to address the chrono-stratigraphic, ecological, environmental, and behavioral patterns involved in the disappearance of the Oldowan and the advent of the Acheulean. Thus, the objectives of this paper are to: 1) describe a classification scheme for the raw materials used in the manufacture of lithic artifacts at Olduvai Gorge, based on outwardly visible properties of rocks excavated by OGAP in Bed II; 2) further characterize the lava raw materials using bulk geochemistry, x-ray diffraction derived mineral assemblages, and thin section description; 3) compare stone tool lava compositions to compositions of lavas from nearby volcanoes to assess source; and 4) report and compare raw material distribution in two excavated assemblages - one late Oldowan (HWK EE) and one early Acheulean (EF-HR), two sites that are investigated monographically in accompanying papers (e.g., Pante et al., submitted; Pante and de la Torre, submitted; de la Torre et al., submitted "a", "b"; Arroyo and de la Torre, submitted; de la Torre and Mora, submitted "a", "b"); and (5) assess the role of hominin raw material selection in the formation of these lithic assemblages.

\section{Materia and methods}




\section{Materials}

Macroscopic classification subgroups were established from the sample available in the lithic assemblages excavated by OGAP at the outcrops of EF-HR, HWK EE, MNK, and FC, and by Mary Leakey at HWK EE. Three collections from two sites were analyzed for this paper, namely HWK EE (OGAP and Leakey collections) and EF-HR (OGAP assemblage). In total, this study considered 20,956 artifacts from HWK EE (which form an aggregate of $\sim 686 \mathrm{~kg}), 2317$ stone tools from EF-HR ( 223 kg), and 4339 unmodified lithics from HWK EE $(\sim 436 \mathrm{~kg})$. The depositional contexts of the two sites are explored in more depth in de la Torre et al. (submitted, "a" and "b"), and their paleoecology is further described in Bibi et al. (submitted), Uno et al. (submitted), Prassack et al. (submitted), and Rivals et al. (submitted). An updated chrono-stratigraphic model of HWK EE, EF-HR, and other relevant Lower, Middle, and Upper Bed II sites is presented in McHenry (submitted) and Stanistreet et al. (submitted), and summarized in Figure 2.

The entire HWK EE-OGAP archaeological $(n=18,107)$ and unmodified $(n=4339)$ lithic assemblage was classified according to general raw material groups. Features of the conglomerate at HWK EE and their implications for the formation of the archaeological assemblage are discussed in de la Torre et al. (submitted "b"). Due to the conglomeratic context at EF-HR (de la Torre et al., submitted "a") and to the fact that Mary Leakey did not curate most of the unmodified materials at HWK EE (Pante and de la Torre, submitted), our analysis of general raw material groups for these two collections focused on the stone tools (EF-HR, $n=2317$; HWK EE Leakey, $n=2849$ ). In addition, while at HWK EE the unmodified cobbles within the locally preserved conglomerate are sufficient in size and compositional diversity to provide a reasonable raw material source for the lava-derived lithic assemblage, the EF-HR conglomerate lacks the large cobbles required to have served as a source for the handaxes found at this site.

Hand-sample examination of rock type subgroups was conducted in full for the HWK EE OGAP collections and EF-HR, but only for the lavas from the HWK EE Leakey collection (therefore in the latter non-extrusive rock classification was limited to general raw material groups). Methods

All stones collected (modified and unmodified) from excavations were characterized by raw material type using hand-sample examination with a hand lens. Samples were sorted into major categories (typically basalt, trachyte, phonolite, quartzite, chert) and then further subdivided based on other characteristics (such as grain size, color, minerals identified, and vesicularity). Samples were characterized without breaking to expose fresh surfaces; in many cases weathering rinds interfered with classification, particularly those involving color.

A classification scheme was developed based on these criteria visible in hand samples, subdividing the total variety of raw material types into categories that could be used to help compare between different excavations, to raw materials available in contemporary fluvial deposits, and to compare to potential source areas. This 
macroscopic classification scheme is presented in Table 1 and pictures are available in the Supplementary Online Material (SOM) 1. Stones other than lavas were characterized only using properties that could be discerned in hand samples (by visual inspection, or with a 10x hand lens), and were classified based on their appearance (e.g., rock type, grain size, color, minerals present). Quartzites were predominantly categorized based on their grain size (fine, medium, coarse) and on the presence or absence of planar muscovite features, and then further subdivided based on color. Chert was categorized based on color and degree of weathering.

In addition to classification of raw material into general groups and specific subgroups, where possible flaked and pounded artifacts were also classified as blocks or cobbles $(>64 \mathrm{~mm}) /$ pebbles $(<64 \mathrm{~mm})$ according to shape and cortex features: although a short residence time in fluvial contexts cannot always be completely ruled out, angularity and absence of fluvial roundness in natural edges of lithics was normally considered as evidence of blocks being transported from primary sources, rather than river conglomerates. Polished cortex and rounded shapes of unmodified areas of blanks were attributed to a conglomeratic origin (i.e., cobbles procured from secondary sources).

A small number $(n=1-3)$ of representative samples from each of the volcanic raw material types were selected for further (destructive) analysis. Wherever possible, non-modified examples were selected to avoid damaging archaeological materials. These were thin sectioned and powdered for geochemical and mineralogical analysis. Powdered samples were then prepared and analyzed by x-ray diffraction (XRD), loss on ignition (LOI), and X-ray fluorescence (XRF). Three quartzite thin sections were also prepared, and two quartzite samples were prepared for and analyzed by XRF.

Thin sections were inspected and described using a petrographic microscope, and images were collected for each section showing representative (and distinctive) features. Point counts were determined by stepping the slide across the stage and identifying the mineral (or void) at the center of the cross-hairs for each step. Between 200 and 400 points were counted for each. For small grains, it was sometimes difficult to determine the exact kind of feldspar present (plagioclase or orthoclase). Where polysynthetic twinning is apparent, or where plagioclase was the only feldspar identified by XRD, feldspars were indicated as plagioclase. Where grains were too small to definitively show polysynthetic twinning, and where multiple types of feldspar were identified using XRD, groundmass feldspars are instead categorized as feldspar (undifferentiated). If phenocrysts are present, the length of the largest was measured.

Samples were initially powdered using a shatterbox, and then a subsample was further reduced in grain size using an agate mortar and pestle. This fine powder was mounted as a random powder and analyzed using a Bruker D8 Focus X-ray Diffractometer $\left(\mathrm{Cu} \mathrm{K} \alpha\right.$ radiation, $1 \mathrm{~s}$ per $0.02^{\circ} 2 \theta, 2^{\circ}-60^{\circ}$ range, scintillation detector). Minerals were identified using Bruker's EVA software, comparing against the ICDD PDF-2 database. Mineral abundances were qualitatively estimated by comparing relative 
peak heights, and categorized as abundant (XXX), common (XX), between common and rare $(\mathrm{X})$, rare $(+)$, and absent $(-)$.

A $~ 1 \mathrm{~g}$ subsample of powdered samples (from the shatterbox) was then analyzed for LOI. A precisely weighed dried sample was placed in a pre-ignited ceramic crucible and heated in a muffle furnace at $1050^{\circ} \mathrm{C}$ for 15 minutes. The sample weight before and after ignition was then used to calculate the LOI.

A $1.000 \mathrm{~g}$ subsample of each of the shatterbox-powdered samples was then prepared for XRF analysis by fusion. It was combined with $10.000 \mathrm{~g}$ of a 50/50 lithium tetraborate/lithium metaborate flux with an integrated $\mathrm{LiBr}$ non-wetting agent, along with $\sim 1 \mathrm{~g}$ of ammonium nitrate as an oxidizer. These were fused at $\sim 1050^{\circ} \mathrm{C}$ in a Claisse M4 Fluxer. Each glass bead was then analyzed in a Bruker S4 Pioneer Wavelength Dispersive X-ray Fluorescence Spectrometer (WD-XRF) for major, minor, and some trace elements. Concentrations were calculated using a calibration derived from eleven USGS rock standards (igneous and sedimentary), using the methods of McHenry (2009) and further detailed in Byers et al. (2016). Concentrations are reported for all elements for which the calculated concentration exceeds two times the lower limit of detection (LLD) and for which the analytical error is less than $12 \%$ (for trace elements) or $2 \%$ (for major elements).

\section{Results}

\section{Geochemistry and mineralogy}

For the lavas, the XRF results were used to further classify the groups based on their bulk composition (Table 2). Using a Le Bas et al. (1986) alkali versus silica plot (Fig. 4a), compositional names (e.g., basalt, trachyte, trachyandesite) were assigned to each sample. In many cases these bulk geochemistry-based designations match those assigned based on macroscopic hand sample description; e.g., all "phonolites" from hand samples plotted in the phonolite or tephriphonolite range. Samples classified as trachytes and basalts all plotted on a continuum between these two end members, as basalts, trachybasalts, trachyandesites, and trachytes. Our hand sample classifications, which relied in part on the color of weathered surfaces, matched some (but not all) of the bulk geochemical classification for basalt and trachyte samples. The two quartzite samples analyzed by XRF had $97 \%$ or higher $\mathrm{SiO}_{2}$ concentrations, with minor amounts of $\mathrm{K}_{2} \mathrm{O}$ and $\mathrm{Al}_{2} \mathrm{O}_{3}$, likely attributable to muscovite. Loss on ignition serves as a proxy for the degree of weathering for the lava samples analyzed; most samples analyzed were minimally weathered, but some were more significantly degraded, especially the phonolite samples.

Mineral identifications based on XRD are reported in Table 3. Example XRD plots (including samples from the major volcanic raw material categories) are shown in Figure 5. The XRD results are consistent with the general categories and XRF results in 
terms of volcanic rock classification; those in the phonolite categories all contain the feldspathoid mineral nepheline (many also contain sodalite and/or analcime), consistent with their silica undersaturated bulk compositions. The phonolites also appear to be the most altered, in some cases with LOIs higher than $4 \%$ and a mineral assemblage that includes low-temperature zeolites (phillipsite and/or chabazite), consistent with alteration under saline-alkaline conditions at Olduvai (McHenry, 2010). Zeolites are not observed in the trachytic or basaltic groups, though minor amounts of smectite are observed in some, consistent with incipient alteration. The basalt and trachyte groups consist mainly of varied amounts of feldspar (anorthoclase, sanidine, and/or plagioclase), augite, and titanomagnetite, with rare amphibole, aenigmatite, and perovskite in some samples.

The point counting results (SOM 2) corroborate the XRD results, help distinguish contributions from phenocrysts from contributions from the groundmass, and help establish the level of vesicularity. Example thin section photomicrographs for each of the major igneous raw materials groups (trachyte, phonolite, basalt) are presented in Figure 6 , and thin sections for all igneous raw material sub-groups are presented in SOM 3.

Three quartzite samples (one from Naibor Soit, and two from Naisiusiu) were thin sectioned and examined petrographically (Fig. 7). The Naibor Soit sample consisted almost entirely of coarse-grained, interlocking quartz crystals, with no direct evidence preserved for original sedimentary textures. Small crystals of muscovite are observed both within individual quartz grains and at grain boundaries, showing only minor alignment. The Naisiusiu thin sections contain finer grained quartz that exhibits more obvious undulose extinction, and contain a larger variety of other minerals (including rare microcline). Both Naibor Soit and Naisiusiu quartzite would be classified as metaquartzites rather than orthoquartzites due to this high level of recrystallization and lack of remnant sedimentary textures, though both formed through metamorphism of sandstones (Hay, 1976).

\section{Analysis of archaeological assemblages}

Rock types. In terms of number of stone tools, quartzite is the most abundant rock type in both HWK EE $(n=18,400)$ and EF-HR $(n=1020)$, although the percent is twice as high in HWK EE (87.8\%) as in EF-HR (44\%; Table 4). The latter shows a higher diversity of rock types, with much larger numbers of basalts (30.7\%, as opposed to $3.4 \%$ in HWK EE), phonolites (13\% versus $4.9 \%$ ), and trachyte-trachyandesites (9.9\% versus $1.6 \%$; Fig. 8a).

Quartzite is still predominant at HWK EE in terms of total weight $(\sim 231 \mathrm{~kg}$, $33.7 \%)$, but is now closely followed by phonolite $(\sim 180 \mathrm{~kg}, 26.3 \%)$ and basalt $(\sim 168 \mathrm{~kg}$, $24.6 \%)$. While relative frequency of quartzite artifacts was also the highest at EF-HR, the predominant rock type weight-wise is basalt ( $\sim 86 \mathrm{~kg}, 38.5 \%)$, with nearly twice as much raw material as quartzite $(\sim 45 \mathrm{~kg}, 20.3 \%)$, and is followed by trachyte-trachyandesite (56 kg, 25.1\%; Fig. 8b). 
Raw material groups. Table 5 shows stone tool counts based on the hand-sample classification. At HWK EE, most $(n=4613 ; \sim 113.5 \mathrm{~kg}$ ) of the analyzed quartzite artifacts fall within raw material (RM) group 7.1 and its variants. Among the phonolites (the second most abundant group numerically and weight-wise at HWK EE), RM group $1.1(n=514$; $\sim 81 \mathrm{~kg}$ ) dominates $(13.7 \%$ of the total weight of the entire stone tool collection and $45.5 \%$ of the phonolite assemblage). Raw material group 3.2 is the most abundant among basalts ( $\sim 51 \mathrm{~kg} ; 30.8 \%$ of the group weight). Trachyte-trachyandesite rocks are dominated by RM group $2.2(n=102 ; \sim 31 \mathrm{~kg})$, which constitutes $32.3 \%$ of the total weight of this raw material (see also Fig. 8f). EF-HR quartzite is also dominated by RM group 7.1 ( $n=753 ; 42 \mathrm{~kg}$ ). Group $2.4(n=251 ; \sim 28 \mathrm{~kg})$ dominates EF-HR basalts $(32.4 \%$ of this raw material) and is also the second most abundant (after 7.1) of the entire assemblage (12.7\%), followed by trachyte-trachyandesite group $2.8(\sim 20 \mathrm{~kg} ; 9 \%$ of the assemblage total weight; see also Fig. $8 \mathrm{~d})$. Raw material group $1.1(n=162 ; \sim 11 \mathrm{~kg})$ constitutes $5.1 \%$ of the overall assemblage weight and dominates EF-HR phonolites.

As compared in Figure $8 \mathrm{~g}$, the distribution of EF-HR quartzite subgroups is relatively similar to that of HWK EE, although group 7.1 at EF-HR contains more $\mathrm{kg}$ of raw material ( $29 \mathrm{~kg} ; 67.2 \%$ of the EF-HR quartzite total weight) than 7.1 .1 (which is the most represented at HWK EE), reflecting a difference in muscovite abundance in otherwise similar coarse-grained quartzites. Figure $8 \mathrm{e}$ shows that the relative frequency of the main phonolite groups is similar in both assemblages, with 1.1 as the most represented $(45.5 \%$ and $35 \%$ of the phonolites in HWK EE and EF-HR, respectively). Distribution of trachytetrachyandesite subgroups in Figure 8e shows a wider variety at HWK EE, although in both assemblages group 2.3 is the second most abundant. Differences between the two assemblages are clearer among the basalts, with two distinctive peaks (subgroup 2.4 in EFHR and 3.2 in HWK EE) and two additional opposite trends-i.e., higher frequency of groups 3.3-3.5 in EF-HR and of groups 2.7 and 3.7 varieties in HWK EE (see Fig. 8h).

Technological groups. The overall number of stone tools at HWK EE $(n=17,408)$ is dominated by quartzite detached pieces, followed by much smaller amounts of phonolite $(n=412)$ and chert $(n=322$; see details in Table 6). Figure 9a-b shows that quartzite also dominates HWK EE flaked pieces (42.4\%), again followed by phonolite (25.5\%), and much lower percentages of basalt (18.3\%) and trachyte-trachyandesite (8\%). Quartzite dominates pounded artifacts at HWK EE (33.8\%) as well, although in this category basalt, phonolite, and trachyte-trachyandesite rocks show nearly identical frequencies of $21-22 \%$. In terms of weight, frequency patterns are similar for detached and pounded artifacts (see Table 6), but different in flaked pieces, where quartzite and phonolite have nearly identical representations of $\sim 29 \%$, followed closely by basalt $(27.5 \%)$.

In EF-HR, the number of objects per raw material/category indicates the dominance of quartzite (47.5\%), basalt (11.7\%), and trachyte-trachyandesite $(7.6 \%)$ detached pieces, with a slightly higher proportion of basalt (29.7\%) flaked pieces over quartzite $(28.5 \%)$, followed by trachyte-trachyandesite (21\%) and phonolite (19.5\%; Table 6). The number of pounded artifacts shows a different pattern, dominated by basalt $(38 \%)$, similar proportions 
of trachyte-trachyandesite (24\%) and phonolite (22\%), and much lower frequency of quartzite $(14 \%)$. With regards to total weight per raw material, basalt dominates both detached (39.3\%), flaked (37.1\%), and pounded (42.7\%) artifacts, followed by quartzite among detached pieces $(31 \%)$ and trachyte-trachyandesite in flaked $(28.3 \%)$ and pounded $(26.2 \%)$ artifacts.

The chi-square test confirms that there are statistically significant differences in the raw material distributions of HWK EE and EF-HR $\left(\mathrm{X}^{2}(25)=9345.05, p<0.0001\right)$. Such differences are significant in all raw material/categories compared except for detached quartzites (Fisher's exact test, $\alpha=0.05$ ), and are conspicuous in Figure 9b and 9e; although quartzite is the prime raw material among detached pieces of both sites, its predominance is more acute at HWK EE, while in EF-HR, detached pieces of basalt are also abundant. Phonolite proportions are similar at both sites in the number of pounded pieces (Fig. 9b) and the total weight of detached artifacts (Fig, 9e). Although marginal in proportion to other raw materials, the regular presence of chert in HWK EE detached and flaked tools is another distinctive feature when compared to EF-HR.

Textural and shape features. A breakdown of raw materials according to grain size/presence of large crystals and vesicularity is shown in Table 7. In HWK EE, 79.4\% of stone tools are coarse-grained and/or have a porphyritic texture. Coarse-grained quartzite is the most abundant $(64.1 \%)$ in the assemblage, followed by coarse grained/porphyritic phonolite. Fine-grained rocks are much less abundant in terms of artifact frequency (15.5\% of the total number of artefacts), although they constitute $33.7 \%$ of the total weight at HWK EE, mostly due to the significant contribution of fine basalt $(\sim 149 \mathrm{~kg})$ and trachytetrachyandesite $(\sim 40 \mathrm{~kg})$ tools.

In EF-HR, $57.7 \%$ of artifacts are porphyritic and/or coarse grained (with coarse quartzite being the most abundant group again), and $40.1 \%$ fine grained (with basalts contributing $31.6 \%$ to the whole assemblage). Relative proportions are similar in terms of weight, although the overall weight of vesicular artifacts is more significant (see details in Table 7). Although fine grained basalt stone tools are numerically less abundant than quartzite, their contribution to the total weight of the assemblage $(31.3 \% ; \sim 62 \mathrm{~kg})$ is more significant than that of coarse quartzite $(21.3 \% ; \sim 42 \mathrm{~kg})$.

As illustrated in Figure 9c and 9f, coarse grained/porphyritic raw materials predominate over fine grained rocks in both HWK EE and EF-HR. Still, the chi-square test points to statistically significant differences between the two sites $\left(\mathrm{X}^{2}(4)=598.67, p<\right.$ $0.0001)$, with the Fisher's exact test $(\alpha=0.05)$ confirming differences in the distribution of fine, medium-fine, and coarse/porphyritic rocks. Quantities of fine-grained artifacts are proportionally more important in EF-HR than at HWK EE, but their overall weight contribution is similar in both sites. HWK EE contains a much higher number of chert artifacts(see values in Table 7). Medium-fine quartzite has a higher amount (4.3\%) and weight at HWK EE (2.2\%), while vesicular rocks at this site contribute a much lower frequency $(2.1 \%)$ of the total weight than at EF-HR (7.1\%). 
With regards to blanks used to flake/pound stone tools, Table 8 indicates that $100 \%$ of phonolite, trachyte-trachyandesite, and basalt have a fluvial origin (rounded cobbles and pebbles). These are normally larger than $>64 \mathrm{~mm}$ (i.e., cobble size), but in the case of HWK EE phonolite, smaller rounded blanks were also frequently used. All chert cores (see frequencies in Table 6) were flaked on nodules, and gneiss artifacts used relatively angular blanks. Quartzite shows greater variability than other rock types, and although angular blocks predominate at HWK EE (see Table 8), fluviatile quartzite is more abundant than angular blanks at EF-HR.

Modified and unmodified rock types at HWK EE. Table 9 shows clear raw material differences in the number of artifacts and unmodified lithics (see also Fig. 10a), which are confirmed by the Chi-square test $\left(\mathrm{X}^{2}(9)=11468.80, p<0.0001\right.$; the Fisher's exact test $[\alpha$ $=0.05]$, indicates significant differences in all raw materials excepting quartz and gneiss). The most conspicuous is the sheer dominance of quartzite stone tools $(89.6 \%)$, while this raw material only includes $22.6 \%$ of unmodified material. Conversely, feldspar is numerically the most abundant unmodified rock type (37.3\%), while its relative frequency among stone tools is negligible. As illustrated in Figure 10e, such imbalance in feldspar frequency fades out when total weight contributions are considered, but overrepresentation of worked quartzite is maintained (34.2\% versus $2.3 \%$ in unmodified material). While weight contribution of worked phonolite $(\sim 113 \mathrm{~kg} ; 24.9 \%$ of total weight of stone tools $)$ is similar to that of unmodified phonolite $(\sim 103 \mathrm{~kg} ; 23.7 \%)$, Figure $10 \mathrm{~d}$ highlights the predominance of unmodified basalt $(\sim 227 \mathrm{~kg})$, which is overrepresented $(52.2 \%$ of total unmodified weight) when compared to basalt stone tools ( $\sim 11 \mathrm{~kg} ; 24.5 \%$ of overall artefact weight).

Comparison of rock texture (Table 10) reveals that coarse/porphyritic quartzite pieces are the most abundant among stone tools (69.9\%), whereas fine basalts predominate among unmodified material (44.2\%; see also Fig. 10b). Coarse/porphyritic quartzite is still the main contributor to the overall weight of stone tools $(30.5 \%)$, but relative frequencies of other rocks such as phonolite (24.9\%) and basalt (21.8\%) follow closely. Predominance of fine-grained basalt among unmodified rocks is more acute when overall weight is considered (see Table 10), as it represents nearly half of the unmodified assemblage, with twice as many $\mathrm{kg}$ as the next largest group (i.e., coarse/porphyritic phonolite: $24 \%$; Fig. 10f).

As shown in Figure 10c and 10g, clear differences are observed in the proportions of rock types per textures: number of pieces of chert, quartz, and medium/fine- grained quartzite on the one hand, and coarse quartzite and gneiss on the other, appear almost exclusively as stone tools, and fine-grained phonolite is also significantly more abundant among archaeological material than in unmodified rocks. These patterns are generally maintained weight-wise (Fig. 10g), which also highlights the prevalence of very coarse grained unmodified pegmatite.

When rock types are consolidated into general textural groups (Fig. 10d and h), a strong pattern emerges, which is consistent in terms of both the number of pieces and the 
overall weight contribution; the unmodified lithic sample is dominated by fine-grained rocks, as opposed to predominant coarse-grained/porphyritic stone tools. Medium-fine grained rocks are more abundant among stone tools than in the unmodified sample, while vesicular rocks usually remain unmodified.

\section{Discussion}

\section{Methodological considerations}

The results of the geochemical composition-based "check" on the hand samplebased raw material classifications highlights the difficulties of categorizing materials without access to fresh surfaces. All phonolite categories were confirmed as phonolite or tephriphonolite in bulk composition (Fig. 4a); the presence of visible nepheline and/or the green color of weathered samples makes this classification easy. However, for the trachytes and basalts, classification based on weathered and unbroken hand samples often differed from classification based on bulk geochemistry. Out of 29 basalt or trachyte samples characterized both in hand samples and geochemically, only five resulted in an exact match (e.g., a "trachyte" plotting in the trachyte field on the TAS diagram in Fig. 4a), and an additional twelve were acceptably close, plotting in adjacent fields (e.g., a "trachyte" plotting as a trachyandesite). Four plotted within two fields (e.g., a "trachyte" plotting as a basaltic trachyandesite) and eight were incorrect (e.g., a "basalt" plotting as a trachyte or trachyandesite). There was also some variability within raw material groups, where one sample plotted correctly and another did not (HWK EE L1-3224 and HWK EE LCHA636, both assigned to basaltic group 3.2.1, but geochemically characterized as basalt and trachyandesite, respectively), which makes it difficult to just reassign all members of a raw materials group to a more appropriate group based on the geochemical composition of an individual sample.

These extreme cases were more common for finer grained samples or "reddened" samples, where the color of weathered surfaces was a major factor in classification (e.g., HWK EE L6-101: basalt RM group 3.7.2, geochemically classified as trachyte, and HWK EE LCHA-636: basalt RM group 3.2.1, geochemically classified as trachyandesite). Previous researchers have also found that fine-grained volcanic materials are more easily misidentified in the field and that geochemical methods may be required to correctly categorize them (e.g., Calogero et al., 1992; Hermes and Ritchie, 1997; Hermes et al., 2001). Where phenocrysts were observed, samples for which feldspar dominated were most likely to be re-classified as more trachytic and those dominated by mafic phenocrysts were more likely to be reclassified as more basaltic. This highlights the need for geochemical analysis to support raw materials classifications based on unbroken, weathered surfaces.

For coarser samples, the geochemical analyses allowed for better classification, as the relationship between phenocrysts and bulk geochemical composition makes reclassification easier. Based on the geochemical results and a subsequent reexamination of 
example hand samples, RM group 3.6 was discontinued, with its members reassigned to group 2.1 or 2.2 depending on the presence of large feldspar phenocrysts. It was also discovered, during the process of making thin sections and breaking down larger specimens for powdering in the shatterbox, that light colored, weathered surface coatings often masked darker interiors. Some specimens categorized as trachytes based on the light color of their unbroken, weathered surfaces would have been classified as basalts had we had access to a fresh, broken surface at the time of categorization (e.g., EF-HR L2- 2033). However, since we cannot break and expose fresh surfaces on every piece in the archaeological collection, we cannot use this as a criterion. These geochemical classifications were considered when assigning specific raw material groups to the "basalt" or "trachyte-trachyandesite" categories for statistical analysis of the assemblage (Table 5).

While this study benefited from detailed petrographic and geochemical analysis of raw materials as a "check" on raw material classification based on hand sample examination alone, such an analysis could not be reasonably applied to an entire collection due to time, effort, and the need for destructive analysis. However, the analysis of representative samples of raw material groups identified in hand samples using the methods described can help determine the validity of these groups and identify the raw material types most likely to be confused or misidentified. The use of non-destructive methods (e.g., hand-held ED-XRF: Braun et al., 2008, 2009a) for geochemical analysis of fine-grained archaeological materials can also help provide this kind of information.

\section{Source considerations}

A comparison of published XRF-determined lava compositions from the adjacent NVH volcanoes (from Mollel, 2007; Mollel et al., 2008, 2009, 2011) provides constraints for likely volcanic sources. A silica-alkali plot after Le Bas et al. (1986) shows the volcanic rock type classifications for both the Olduvai lithics and the potential NVH sources (Fig. 4b). Lemagurut, Ngorongoro, and Olmoti lavas all provide an overlapping continuum of compositions from basalt through trachyandesite, while Olmoti lavas also include trachytes and Ngorongoro lavas also include trachydacites. While Ngorongoro is also known to produce rhyolites (e.g., Hay, 1976; McHenry et al., 2008), these tend to be in the form of ash or ignimbrites rather than lavas and thus lack properties desirable for tool-making. The basalt to trachyandesite continuum from these three volcanoes closely overlaps the basalt to trachyandesite trend also observed in the Olduvai lithics, but does not provide additional source information based on bulk composition alone.

Satiman and Engelosin both produced phonolites, which overlap with phonolite compositions observed in the Olduvai lithics. However, most Satiman lava samples analyzed by Mollel et al. (2011) plot in the phonotephrite to foidite range, with lower silica concentrations compared to those in the Olduvai lithics. None appear to overlap the range of the majority of the Olduvai lithic phonolites, which fall mostly in the

tephriphonolite range. It should be noted that Mollel et al.'s (2011) Satiman samples were 
collected from outcrops near the current summit of the highly eroded volcano and may not be representative of the variety of Satiman-derived phonolitic lava compositions that would have eroded into the Pleistocene Olduvai basin. Satiman and Engelosin are the only known phonolite-producing volcanoes of the appropriate age directly adjacent to the Olduvai basin, and it is therefore unlikely that hominins would have had access to phonolites from another volcanic source.

As Hay (1976) and Tactikos (2005) established, Naibor Soit and Naisiusiu quartzites can roughly be distinguished based on their grain size. Naibor Soit quartzites are coarse to very coarse grained, and often have planar muscovite features (Hay, 1976), while Naisiusiu quartzites are typically medium-fine grained and not as rich in muscovite (Tactikos, 2005). Our quartzite subcategories (especially those based on color) are more intended to help identify refits than to link them to a specific outcrop source. The proximity of Naibor Soit to both HWK EE and EF-HR (compared to other metamorphic inselbergs, such as Naisiusiu) would have made its quartzite more accessible as a primary source. We do not exclude that the shorter transport distance between Naibor Soit and the archaeological sites (compared to the NVH volcanoes) could explain the higher angularity of quartzite compared to lava cobbles, and therefore that the Naibor Soit could have also been a source for quartzite cobbles in local streams, which could have served as a secondary source. However, most quartzite block blanks at the archaeological sites show no signs of abrasion, and therefore it is likely they were introduced by hominins from primary sources. There are, in addition, well- rounded quartzite cobbles that clearly have a secondary-source origin. Rare occurrences of finer grained quartzite (likely Naisiusiu) and gneiss (Kelogi, or far-western Olduvai Main Gorge) in the archaeological assemblages could point towards longer transport distances for these alternative quartzite sources.

Chert nodules were formed during specific intervals within the saline-alkaline lacustrine sediments of paleolake Olduvai and can be found in outcrop in the Side Gorge around the time of Tuff IIA (Hay, 1976). Erosion of chert-bearing lacustrine sediments, likely associated with the withdrawal of the lake during a lowstand, could have exposed this new resource. The chert nodules could have been collected in situ, or from stream beds that drained areas from which they were eroding, and since the Tuff IIA interval is cut out in places by the disconformity directly underlying the upper levels of the HWK EE assemblage (Hay's [1976] Lower Augitic Sandstone [LAS]: de la Torre et al., submitted, "b"), we would expect such a resource to be accessible at that time. During times of lake transgression, or when chert-bearing outcrops were not actively being eroded, chert would have been much less available. This helps explain why chert artifacts are rare or absent from many Olduvai archaeological assemblages, but ubiquitous in others (e.g., Stiles et al., 1974; Kimura, 1997, 1999).

The MNK chert factory site, described in detail by Stiles et al. (1974), sits upon a disconformity that Hay (1976) associates with the LAS in the Main Gorge. This stratigraphic placement could make the MNK chert factory site (and its abundant chert 
artifacts, described by Stiles et al. [1974]) contemporaneous with the bulk of the HWK EE lithic assemblage. The significantly lower proportion of chert artifacts in HWK EE could be due in part to a slight difference in age of the materials infilling the LAS-related incision, or because drainages in the vicinity of HWK EE during the deposition of the LAS largely transported materials from east to west (e.g., Hay, 1976). HWK EE also lacks the local potentially primary source of chert offered by in situ chert-rich layers observed at MNK above the level of Tuff IIA.

\section{Archaeological significance}

The numerical prevalence of quartzite artifacts in both HWK EE and EF-HR is clearly due to the dominance of detached pieces of this raw material. While in HWK EE raw material contributions to the total weight also indicate the predominance of quartzite (see de la Torre and Mora, submitted "a" for an extended discussion), in the case of EF$\mathrm{HR}$, basalt is the prime rock type in all technological categories. This stresses the need to differentiate degree of fragmentation (which concerns the actual number of pieces and that in both sites is clearly highest for quartzite) from the total number of rock units originally processed by stone-tool makers, and from the overall contribution of each raw material to the archaeological assemblage (which is better assessed by considering the total weight of each rock type). From this perspective, Figure $8 \mathrm{~b}$ shows that rock type relative proportions are not exceedingly disparate in either site, with prevalence in HWK EE of quartzite, followed by phonolite and basalt, and of basalt, trachyte-trachyandesite, and quartzite in EF-HR.

The eastern end of Naibor Soit hill (main source of coarse quartzite) is approximately $1.9 \mathrm{~km}$ in a straight line from the main trench at EF-HR, and HWK EE is at a similar distance, $\sim 2 \mathrm{~km}$ from this source. Therefore, geographic distance alone does not explain preferential use of quartzite in HWK EE when compared to EF-HR. In fact, many of the analyzed quartzite blanks in the latter site have a fluvial origin, and therefore were not transported by humans from the original source at Naibor Soit, but rather collected from river streams. Even at HWK EE, where quartzite blocks are predominantly angular and likely sourced directly from Naibor Soit, river cobbles of this raw material amount to a minimum of $20 \mathrm{~kg}$, thus highlighting that caution is needed when linking raw material transport and site distance to Naibor Soit exclusively (e.g., the "distance-decay" model of Blumenschine et al. [2008, 2012]). In other words, even when quartzite was originally derived from the Naibor Soit outcrop, in some cases the shape of the blanks points towards a fluvial source for raw materials used by hominins, rather than a direct human transport from the hills of Naibor Soit. Additionally, a small percentage of the quartzite assemblage is medium to fine grained at both sites, pointing towards a different origin from Naibor Soit, potentially Naisiusiu hill or stream clasts eroded from other metamorphic outcrops in the basin. A non-Naibor Soit source cannot be ruled out for varieties such as group 7.5 (dark medium quartzite consistently present in HWK EE) and 7.2 (fine grained quartzite also present in HWK EE and in EF-HR). 
Fluvial provenance of the entire lava assemblage is well attested in both sites (see Table 8), normally in the form of clasts $>64 \mathrm{~mm}$, although pebble-sized lavas are also present. Lavas contribute most of the total weight of stone tools in both HWK EE $(64.9 \%)$ and EF-HR (78.9\%; see Table 4) and, therefore, it can be assumed that access to stream sources took place in both Oldowan and Acheulean times. Nonetheless, some differences are observed. For instance, the virtually reversed trend in phonolite $(26.3 \%$ in HWK EE versus $15.3 \%$ in EF-HR) and trachyte-trachyandesite (14\% in HWK EE versus $25.1 \%$ in EF-HR) could potentially be explained by the geographic location of sites, with EF-HR being closer to Olmoti trachytic sources and HWK EE closer to the fluvial network draining Satiman and transporting its phonolites (see Fig. 3). The case of basalt is even more interesting; this raw material contributes most of the total weight to the EF-HR stone tools (38.5\%: see Table 4), a proportion that is mirrored in the unmodified assemblage of HWK EE (38.1\%: Table 9), but which is much lower within the HWK EE stone tool collection (24.5\%). The extensive deposit of unmodified lava cobbles at the HWK EE site is interpreted as a secondary raw material source, reflecting the raw material availability in the surroundings. Under this assumption, it can therefore be interpreted that Oldowan hominins did not choose basalt in proportion to its availability, and instead selected phonolites preferentially.

Chert presents negligible percentages in EF-HR and very low percentages in HWK EE (see Table 4), but is relevant for the interpretation of technology (de la Torre and Mora, submitted "b") and taphonomy (de la Torre et al., submitted "b") of the latter, and thus merits discussion. Continuous presence of chert throughout the archaeological sequence of HWK EE (see de la Torre et al., submitted "b") is consistent with its stratigraphic position in and above Tuff IIA, as Hay (1976) reported chert beds formed in the Olduvai paleo-lake during this period, and most archaeological assemblages within this interval contain variable quantities of chert (Leakey, 1971; Stiles et al., 1974; Kyara, 1999; Proffitt, submitted). The exact sourcing of chert nodules for hominins is however less well understood, and even in localities where natural availability of chert is attested (e.g., MNK Chert Factory), there is debate as to whether stone tools were made from local or imported chert (Stiles et al., 1974; Kimura, 1997, Proffitt, submitted). In EF-HR, most of the chert is clearly unconnected to the main archaeological assemblage and can be considered as part of the gravel background (de la Torre and Wehr, submitted), probably reworked from earlier Tuff IIA-interval contexts. In HWK EE, however, chert sourcing presents similar interpretive problems as in penecontemporary assemblages; HWK EE chert cores are mostly made on nodules with similar features to those seen in stratigraphic units where chert was formed in situ, such as in the MNK and FC localities (LJM pers. obs.). From that perspective, it could be proposed that HKW EE hominins collected nodules directly from chert-bearing layers formed and exposed during Tuff IIA times. Nonetheless, it is also possible that chert nodules could have been present in Bed II river conglomerates. If so, the extent of clast modification by flowing water could help establish its source, given that chert would be eroded from local chert-forming layers. 
A similar problem is posed by gneiss. Albeit always in very low frequencies, the presence of gneiss is ubiquitous in Bed II sites within the Side Gorge (Leakey, 1971; Hay, 1976; Kyara, 1999), which is consistent with their closer distance to the Kelogi hills in the west, the proposed source for this raw material (Hay, 1976). Therefore, near-absence of gneiss in EF-HR is expected, for this site is located on the eastern side of the basin (Fig. 3). In HWK EE, however, the provenance of gneiss is not entirely clear; if it was sourced by hominins in local river streams, that would imply a fluvial network supplying clasts into the Junction area of Olduvai Gorge from far to the west, a pattern which is not considered in available models for Lower or Middle Bed II (Hay, 1976). Alternatively, hominins sourcing gneiss directly from the Kelogi hills would imply procurement distances of $\sim 9$ $\mathrm{km}$. This option is, however, at odds with the general pattern of local raw materials prevailing at HWK EE, and with the poor flaking qualities of gneiss, which would not warrant high-cost transport efforts. Unfortunately, features of the rare gneiss artifacts recovered at HWK EE (nine pieces in total; see Table 9) do not help to resolve this question; on the one hand, the general lack of sharpness observed in archaeological pieces is also seen in natural blocks outcropping in Kelogi (IdlT pers. obs.), and therefore cannot confidently be attributed to fluvial action, but rather to the textural properties of Kelogi gneiss. On the other hand, the blocky aspect of some archaeological blanks should not be straightforwardly linked to human sourcing from the hills, but could potentially be caused by the relatively short transport distance by river streams. This issue of short residence time applies to the Naibor Soit quartzite, and also to the gneiss from Kelogi, should such streams have existed during the deposition of Bed II. However, the rarity of gneiss in the conglomerate deposits and the overwhelming abundance of volcanic materials derived from the eastern basin and adjacent NVH volcanoes supports overall fluvial transport and sourcing from the east during this time, as reconstructed by Hay (1976) and from our own observations.

Another important point of discussion is the influence of edge durability, shape, and texture in raw material selectivity by HWK EE and EF-HR hominins. Braun et al. (2009c) have argued that selection of raw materials at the Kanjera Oldowan was driven by abrasion resistance, rather than by fracturing predictability. Experiments with Olduvai assemblages (e.g., Jones, 1994; Tactikos, 2005) have also considered edge efficiency in raw material selection, and future work should explore whether the harder silica structure of Olduvai quartzite over lavas played a role in explaining the overabundance of quartzite debitage. It has been demonstrated elsewhere that Oldowan hominins selected preferentially those fine-grained raw materials more apt for flaking (Stout et al., 2005; Harmand, 2005; Braun et al., 2009c; Goldman-Neuman and Hovers, 2012). This is certainly the case for EF-HR, where knappers chose preferentially specific types of highquality fine basalt and trachyte-trachyandesite for their tools (see Table 7) and, in general, they were selecting the best available raw materials to make Large Cutting Tools (de la Torre and Mora, submitted ' $b$ '). In HWK EE, however, better conchoidal properties of fine grained materials were not the only (or the main) selectivity parameter; indeed, hominins were aware of the better flaking qualities of a fine-grained rock such as chert, and thus preferentially used this raw material for retouched tools (see de la Torre and Mora, 
submitted 'a'). Nonetheless, in HWK EE, $\sim 288 \mathrm{~kg}$ of stone tools are coarsegrained/porphyritic, as opposed to $\sim 126 \mathrm{~kg}$ of fine-grained artifacts (see Table 7), and this cannot be linked just to local availability; as discussed above, fine-grained basalt was immediately available, and indeed up to $\sim 227 \mathrm{~kg}$ of unmodified basalts have been unearthed from this site (Table 9). Yet, hominins selected preferentially coarse-grained quartzite, most likely sourced by humans directly from Naibor Soit. We interpret this general avoidance of fine-grained basalt for flaking as due to the shape of the available blanks: in HWK EE, lava cobbles are usually very rounded and lack suitable natural angles to initiate flaking. This, combined with the considerable hardness of local basalts, would have led hominins to use Naibor Soit quartzite preferentially; despite the fact that it was not available in the immediate surroundings of the site and is coarse-grained, it could be collected from Naibor Soit as blocks and slabs with suitable flaking angles.

In summary, our study of the archaeological material from EF-HR and the stone tool and unmodified assemblage from HWK EE has enabled us to make a number of cautionary points and some general patterns about hominin raw material selectivity. Among the first, and following earlier attempts on this matter at Olduvai (de la Torre and Mora, 2005; Blumenschine et al., 2008), we have confirmed the importance of considering weight contribution as a relevant parameter to assess raw material procurement; in a sequential, unidirectional process such as stone knapping, the number of objects better records intensity of reduction or degree of raw material fragmentation, while weight reflects the contribution of each raw material transported to the site more accurately. In addition, a consideration of shape features raises questions about establishing direct links between raw materials and parent sources; this is the case for quartzite, where the rounded shape of many blanks points towards a fluvial origin and, hence, suggests the need to nuance direct correlations between this raw material and human transport from Naibor Soit. Shape also plays a role in human selectivity, which at least in the case of HWK EE, may have overturned preferences based on rock conchoidal properties, as hominins preferred a coarse-grained quartzite with suitable flaking angles from a non-immediate source at Naibor Soit over fine-grained rounded basalts (and lavas in general) that were immediately available.

As a whole, HWK EE raw material procurement is characterized by preferential use of coarse grained quartzite sourced locally $(\sim 2 \mathrm{~km})$ from Naibor Soit hill, which was subjected to a high degree of fragmentation at the site. Lavas were probably available in the immediate surroundings from stream conglomerates and were also used in flaking and pounding activities. Other raw materials such as chert were used more marginally, although hominins were probably aware of its higher quality, and its low frequency might be due to a longer distance of transport, which is currently unknown.

Most of the raw materials from EF-HR derive from river streams, the location of which is also unknown: the composition of the EF-HR local conglomerate is dominated by lavas (de la Torre et al., submitted), but neither the quality nor the size of local clasts match with that of artifacts. This pattern is particularly evident in the Large Cutting Tools, which 
are often made in high-quality basalt and trachyte, and (to a minor extent) phonolite and quartzite. Therefore, it is assumed that EF-HR hominins were selecting preferentially finegrained lavas and large-sized cobbles/boulders, which were non-existent in the local surrounding and were sourced elsewhere (see extended discussion in de la Torre and Mora, submitted "b").

\section{Conclusions}

Olduvai hominins in Lower/Middle (HWK EE) and Upper (EF-HR) Bed II used a wide variety of raw materials in the manufacture of their lithic artifacts, most of which would have likely been available as cobbles in local streams or in outcrops within $2 \mathrm{~km}$ of the sites. Phonolites, and lavas ranging from basalts to trachytes, were originally derived from neighboring volcanoes (Lemagurut, Satiman, Ngorongoro, Olmoti, and Engelosin), though the rounded nature of the blanks employed in toolmaking demonstrates that hominins were making use of local, fluvially transported cobbles, rather than distant outcrop sources. For HWK EE, quartzite artifacts appear to have been manufactured mostly from angular blanks, indicating transport of raw materials from outcrops at Naibor Soit hill, while more rounded quartzite blanks inferred for EF-HR point to fluvial quartzite access rather than outcrop acquisition.

EF-HR hominins used fine-grained basalts and trachytes of high quality to shape Large Cutting Tools from large cobbles and boulders not immediately available at the site. Therefore, raw material selectivity can clearly be proposed in the case of this Acheulean site. Preferential use of chert for retouched artifacts in HWK EE suggests that Oldowan hominins selected this fine grained raw material for particular purposes. However, HWK EE hominins generally prioritized the presence of natural angles on blanks over rock texture; thus, they preferentially flaked Naibor Soit coarse quartzite over fine-grained lavas, despite the fact that the latter were available in the immediate surroundings, whereas quartzite required procurement transport from the rock sources.

Our study also aims to establish methodological protocols that can be applied to the study of future excavated collections. The level of detail in the petrographic atlas presented in this paper, and in the characterization of the volcanic raw materials used and available at these Middle and Upper Bed II sites, will contribute to studies of other sites excavated by OGAP and to our ongoing characterization of the source volcanoes in the adjacent Ngorongoro Volcanic Highlands. Such detailed analysis of representative specimens from different raw material groups originally identified in hand samples can serve as a useful "check" for raw material characterization. More broadly, our protocols and atlas could be expanded and applied to other Beds at Olduvai and could be adapted or used as a template for other eastern African archaeological sites.

\section{Acknowledgments}


We would like to thank the rest of the OGAP research team for their support of this project, especially Dr. Ian Stanistreet, who helped develop the original classification categories, and Carmen Martín Ramos and Steven Greenwood, who provided assistance in the lab. Fieldwork at Olduvai by OGAP was authorized by the Commission for Science and Technology (COSTECH), the Department of Antiquities, Tanzania, and the Ngorongoro Conservation Authority Area. Funding by the NSF (BCS-0852292), the Leakey Foundation (both to LM), and the European Research Council-Starting Grants (283366 to IdlT) is gratefully acknowledged. 


\section{References}

Arroyo, A., de la Torre, I., submitted. Percussive tools in HWK EE and EF-HR. J. Hum. Evol.

Blumenschine, R.J., Masao, F.T., Tactikos, J.C., Ebert, J.I., 2008. Effects of distance from stone source on landscape-scale variation in Oldowan artifact assemblages in the Paleo-Olduvai Basin, Tanzania. J. Archaeol. Sci. 35, 76-86.

Blumenschine, R.J., Masao, F.T., Stollhofen, H., Stanistreet, I.G., Bamford, M.K., Albert, R.M., Njau, J.K., Prassack, K.A., 2012. Landscape distribution of Oldowan stone artifact assemblages across the fault compartments of the eastern Olduvai Lake Basin during early lowermost Bed II times. J. Hum. Evol. 63, 384-394.

Braun, D.R., Plummer, T., Ditchfield, P., Ferraro, J.V., Maina, D., Bishop, L.C., Potts, R., 2008. Oldowan behavior and raw material transport: perspectives from the Kanjera Formation. J. Archaeol. Sci. 35, 2329-2345.

Braun, D.R., Harris, J.W.K., Maina, D.N., 2009a. Oldowan raw material procurement and use: Evidence from the Koobi For a Formation. Archaeometry 51, 26-42.

Braun, D.R., Plummer, T.W., Ditchfield, P.W., Bishop, L.C., Ferraro, J.V., 2009b. 9. Oldowan Technology and Raw Material Variability at Kanjera South. In: Hovers, E., Braun, D.R. (Eds.), Interdisciplinary Approaches to the Oldowan, Springer, Netherlands, pp. 99-110.

Braun, D.R., Plummer, T., Ferraro, J.V., Ditchfield, P., Bishop, L.C., 2009c. Raw material quality and Oldowan hominin toolstone preferences: evidence from Kanjera South, Kenya. J. Archaeol. Sci. 36, 1605-1614.

Byers, H.L., McHenry, L.J., Grundl, T.J., 2016. Forty-nine major and trace element concentrations measured in soil reference naterials NIST SRM 2586, 2587, 2709a, 2710a and 2711a using ICP-MS and qavelength dispersive-XRF. Geostand. Geoanal. Res. 40, 433-445.

Calogero, B.L.A., 1992. Lithic misidentification. Man in the Northeast 43, 87-90.

Curtis, G.H., Hay, R.L., 1972. Further geological studies and potassium-argon dating at Olduvai Gorge and Ngorongoro Crater. In: Bishop, W.W., Miller, J.A. (Eds.), Calibration of Hominoid Evolution Recent advances in isotopic and other dating methods as applicable to the origin of man. Scottish Academic Press, Edinburgh, pp. 289-301.

Deino, A, 2012. ${ }^{40} \mathrm{Ar} /{ }^{39} \mathrm{Ar}$ dating of Bed I, Olduvai Gorge, Tanzania, and the chronology of early Pleistocene climate change. J. Hum. Evol. 63, 251-273.

De la Torre, I., Mora, R., submitted "a". Oldowan technological behaviour at Olduvai Gorge, Tanzania: The HWK EE stone tool assemblage. J. Hum. Evol. 
De la Torre, I., Mora, R., submitted "b". Technological behaviour in the early Acheulean of EF-HR (Olduvai Gorge, Tanzania). J. Hum. Evol.

submittedDe la Torre, I., Wehr, K., submitted. Site formation processes of the early Acheulean assemblage at EF-HR (Olduvai Gorge, Tanzania). J. Hum. Evol.

de la Torre, I., Albert, R.M., Macphail, R., McHenry, L., Pante, M., Rodríguez-Cintas, A., Stanistreet, I., Stollhofen, H. submitted "a". The contexts and early Acheulean archaeology of the EF-HR landscape (Olduvai Gorge, Tanzania). J. Hum. Evol.

de la Torre, I., Albert, R.M., Arroyo, A., Macphail, R., McHenry, L., Mora, R., Njau, J.K., Pante, M.C., Rivera Rondón, C., Rodríguez-Cintas, A., Stanistreet, I., Stollhofen, H., Wehr, K. submitted "b". New excavations at the HWK EE site: archaeology, palaeoenvironment and site formation processes in the basal part of Middle Bed II (Olduvai Gorge, Tanzania). J. Hum. Evol.

Diez-Martín, F., Yustos, P.S., Uribelarrea, D., Baquedano, E., Mark, D.F., Mabulla, A., Fraile, C., Duque, J., Díaz, I., Pérez-González, A., Yravedra, J., Egeland, C.P., Organista, E., Domínguez-Rodrigo, M., 2015. The origin of the Acheulean: the 1.7 million-year-old site of FLK West, Olduvai Gorge (Tanzania). Sci. Rep. 5. 17839

Domínguez-Rodrigo, M., Pickering, T.R., Baquedano, E., Mabulla, A., Mark, D.F., Musiba, C., Bunn, H.T., Uribelarrea, D., Smith, V., Diez-Martin, F., PérezGonzález, A., Sánchez, P., Santonja, M., Barboni, D., Gidna, A., Ashley, G., Yravedra, J., Heaton, J.L., Arriaza, M.C., 2013. First Partial Skeleton of a 1.34Million-Year-Old Paranthropus boisei from Bed II, Olduvai Gorge, Tanzania. PLOS One 8, e80347.

Goldman-Neuman, T., Hovers, E., 2009. 7. Methodological Considerations in the Study of Oldowan Raw Material Selectivity: Insights from A.L. 894 (Hadar, Ethiopia). In: Hovers, E., Braun, D.R. (Eds.), Interdisciplinary Approaches to the Oldowan. Springer, Dordrecht, pp. 71-84.

Goldman-Neuman, T., Hovers, E., 2012. Raw material selectivity in Late Pliocene Oldowan sites in the Makaamitalu Basin, Hadar, Ethiopia. J. Hum. Evol. 62, 353366.

Harmand, S., 2005. Matières premières lithiques et comportements techno-économiques des homininés Plio-Pléistocènes du Turkana Occidental, Kenya. Ph.D. Dissertation, Université Paris X-Nanterre.

Harmand, S., 2009. 8. Variability in Raw Material Selectivity at the Late Pliocene sites of Lokalalei, West Turkana, Kenya. In: Hovers, E., Braun, D.R. (Eds.), Interdisciplinary Approaches to the Oldowan, Springer, Netherlands, pp. 85-97.

Hay, R.L. 1976. Geology of the Olduvai Gorge. University of California Press, Berkeley. 
Hermes, O.D., Ritchie, D., 1997. Nondestructive trace element analysis of archaeological felsite by energy dispersive X-ray fluorescence spectroscopy, Geoarchaeology 12, $31-40$.

Hermes, O.D., Luedtke, B.E., Ritchie, D., 2001. Melrose Green rhyolite: its geologic setting and petrographic and geochemical characteristics. J. Archaeol. Sci. 28, 913 928.

Jones, P.R., 1994. Results of experimental work in relation to the stone industries of Olduvai Gorge. In: Leakey, M.D., Roe, D.A. (Eds.), Olduvai Gorge. Volume 5. Excavations in Beds III, IV and the Masek Beds, 1968-1971. Cambridge University Press, Cambridge, pp. 254-298.

Kimura, Y., 1997. The MNK Chert Factory Site: The chert-using strategy by early hominids at Olduvai Gorge, Tanzania. Afr. Study Monogr. 18, 1-28.

Kimura, Y., 1999. Tool-using strategies by early hominids at Bed II, Olduvai Gorge, Tanzania. J. Hum. Evol. 37, 807-831.

Kimura, Y., 2002. Examining time trends in the Oldowan technology at Beds I and II, Olduvai Gorge. J. Hum. Evol. 43, 291-321.

Kyara, O.A., 1999. Lithic Raw Materials and Their Implications on Assemblage Variation and Hominid Behavior During Bed II, Olduvai Gorge, Tanzania. Ph.D. Dissertation, Rutgers University.

Leakey, M.D., 1971. Olduvai Gorge. Vol 3. Excavations in Beds I and II, 1960-1963. Cambridge University Press, Cambridge.

Le Bas, M.J., Le Maitre, R.W., Streckeisen, A., Zanettin, B., IUGS Subcommission on the Systematics of Igneous Rocks, 1986. A chemical classification of volcanic rocks based on the total alkali-silica diagram. J. Petrol. 27, 745-750.

Manega, P.C., 1993. Geochronology, geochemistry and isotopic study of the PlioPleistocene Hominid sites and the Ngorongoro volcanic highland in Northern Tanzania. Ph.D. Dissertation, University of Colorado, Boulder.

McHenry, L.J., 2009. Element mobility during zeolitic and argillic alteration of volcanic ash in a closed-basin lacustrine environment: case study Olduvai Gorge, Tanzania. Chem. Geol. 265, 540-552.

McHenry, L.J., 2010. Element distribution between coexisting authigenic mineral phases in argillic and zeolitic altered tephra, Olduvai Gorge, Tanzania. Clay. Clay Miner. $58,627-643$. 
McHenry, L.J., submitted. Tephrochronology of Bed II, Olduvai Gorge, Tanzania, and the chronology of the Oldowan-Acheulean transition. J. Hum. Evol.

McHenry, L.J., Mollel, G.M., Swisher III, C.C., 2008. Compositional and textural correlations between Olduvai Gorge Bed I tephra and volcanic sources in the Ngorongoro volcanic highlands, Tanzania. Quatern. Intl. 178, 306-319.

Mollel, G.F., 2007. Petrochemistry and geochronology of Ngorongoro Volcanic Highland Complex (NVHC) and its relationship to Laetoli and Olduvai Gorge, Tanzania.

Ph.D. Dissertation, Rutgers University.

Mollel, G.F., Swisher III, C.C., 2012. The Ngorongoro Volcanic Highland and its relationships to volcanic deposits at Olduvai Gorge and East African Rift volcanism. J. Hum. Evol. 63, 274-283.

Mollel, G.F., Swisher III, C.C., Feigenson, M.D., Carr, M.J., 2008. Geochemical evolution of Ngorongoro Caldera, Tanzania: implications for crust-magma interaction. Earth Planet. Sci. Lett. 271, 337-347.

Mollel, G.F., Swisher III, C.C., McHenry, L.J., Feigenson, M.D., Carr, M.J., 2009. Petrogenesis of basalt-trachyte lavas from Olmoti crater, Tanzania. J. Afr. Earth Sci. $54,127-347$.

Mollel, G.F., Swisher III, C.C., Feigenson, M.D., Carr, M.J., 2011. Petrology, geochemistry, and age of Satiman, Lemagurut and Oldeani: sources of the volcanic deposits of the Laetoli area. In: Harrison, T. (Ed.), Paleontology and Geology of Laetoli: Human Evolution in Context 1. Springer, Dordrecht, pp. 99-119.

Pante, M., de la Torre, I., submitted. A hidden treasure of the Lower Pleistocene: the Leakey HWK-EE assemblage. J. Hum. Evol.

Pante, M.C., Njau, J.K., Hensley-Marschand, B., Keevil, T.L., Martín-Ramos, C., Peters, R.F., de la Torre, I., submitted. The carnivorous feeding behavior of early Homo at HWK EE, Bed II, Olduvai Gorge, Tanzania. J. Hum. Evol.

Prassack, K., Pante, M.C., Njau, J.K., de la Torre, I., submitted. The Paleoecology of Pleistocene Birds from Middle Bed II, at Olduvai Gorge, Tanzania, and the Environmental Context of the Oldowan-Acheulean Transition. J. Hum. Evol.

Proffitt, T., submitted. Diachronic changes in Oldowan technology in Beds I and Lower Bed II. J. Hum. Evol.

Rivals, F., Uno, K., Bibi, F., Pante, M.C., Njau, J.K., de la Torre, I., submitted. Dietary traits of the ungulates from the HWK EE site at Olduvai Gorge (Tanzania): diachronic changes and seasonality. J. Hum. Evol.

Stanistreet, I.G., McHenry, L.J., Stollhofen, H., de la Torre, I., submitted. Sequence stratigraphic context of EF-HR and HWK EE archaeological sites, and the Oldowan/ Acheulean succession at Olduvai Gorge, Tanzania. J. Hum. Evol. 
Stiles, D.N., Hay, R.L., O`Neil, J.R., 1974. The MNK Chert Factory Site, Olduvai Gorge, Tanzania. World Archaeol. 5, 285-308.

Stout, D., Quade, J., Semaw, S., Rogers, M.J., Levin, N.E., 2005. Raw material selectivity of the earliest stone toolmakers at Gona, Afar, Ethiopia. J. Hum. Evol. 48, 365-380.

Tactikos, J.C., 2005. A landscape perspective on the Oldowan from Olduvai Gorge, Tanzania. Ph.D. Dissertation, Rutgers University.

Torre, I. de la, Mora, R., 2005. Technological Strategies in the Lower Pleistocene at Olduvai Beds I and II. Liege: ERAUL 112.

submittedsubmitted

submittedsubmittedsubmittedsubmittedsubmittedUno, K., Uno, Rivals, F., Bibi, F., Pante, M.C., Njau, J.K., de la Torre, I., submitted. Large mammal diets and paleoecology across the Oldowan-Acheulean transition at Olduvai Gorge, Tanzania from stable isotope and tooth wear analyses. J. Hum. Evol. 


\section{Figure captions}

Figure 1. Map showing relative positions of Olduvai Gorge and the neighboring Ngorongoro Volcanic Highlands volcanoes. Base map from the Shuttle Radar Topography Mission, image credit NASA/JPL/NIMA. Lemagurut, Satiman, Ngorongoro, Olmoti, and Engelosin are all directly adjacent to the Olduvai basin and pre-date the deposition of Middle to Upper Bed II, making them potential primary sources for volcanic raw materials.

Figure 2. Composite stratigraphic section of Olduvai Bed II, modified from McHenry (submitted). Marker tuffs and other important stratigraphic markers (Lemuta Member and augitic sandstones), plus the relative stratigraphic positions of the HWK EE and EF-HR archaeological sites, are indicated. Dates derived from (1) Deino, 2012; (2) Curtis and Hay, 1972*; (3) Manega, 1993*; (4) Diez-Martín et al., 2015; (5) Domínguez-Rodrigo et al., 2013. * Indicates dates that have been adjusted for new Ar decay constant (details in McHenry, submitted).

Figure 3. Digital elevation model of the Olduvai basin with location of the main primary raw material sources and position of the two archaeological sites under study (HWK EE and EF-HR), along with other Bed II sites mentioned in the text. Naibor Soit and Naisiusiu are potential outcrop sources for quartzite, Kelogi provides gneiss, and Engelosin, Olmoti, Ngorongoro, Satiman, and Lemagurut could all provide volcanic materials, either as primary sources or as source areas for cobbles available in local drainages.

Figure 4. Total alkalis versus silica diagrams, after Le Bas et al. (1986), for (A) Olduvai lithic materials (this study) and for (B) NVH lavas (published XRF-derived compositions from Mollel, 2007; Mollel et al., 2008, 2009, 2011). In A, individual symbols represent one (or multiple similar) raw material classification category based on hand sample descriptions. All "phonolite" raw materials plot within the phonolite/tephriphonolite/foidite range, indicating silica undersaturated compositions. The various categories of "trachytes" and "basalts" plot in a continuum between basalt and trachyte, with most samples falling between the two end members. In B, Satiman phonolites plot mainly in the phonotephrite range, distinct from the Olduvai lithic tephriphonolites, while lavas from Ngorongoro, Olmoti, and Lemagurut all cover overlapping portions of the continuum between basalt and trachyte.

Figure 5. Example XRD plots, with minerals identified. Ae $=$ aenigmatite, $A n=$ analcime, $\mathrm{Au}=$ augite, $\mathrm{Ch}=$ chabazite, $\mathrm{K}=\mathrm{K}$-feldspar (typically sanidine), $\mathrm{Ne}=$ nepheline, $\mathrm{P}=$ plagioclase, $\mathrm{Ph}=$ phillipsite, $\mathrm{Sm}=$ smectite, $\mathrm{So}=$ sodalite, $\mathrm{Tm}=\mathrm{Ti}$ magnetite. A) EF-HR L1-119 (raw material [RM] group 1.3, phonolite) is dominated by nepheline and augite (with minor K-feldspar) and contains low-temperature zeolites (phillipsite and chabazite), indicating incipient alteration. B) EF-HR L2 691 (RM group 1.4, phonolite) is dominated by feldspar (both plagioclase and K-feldspar) with more nepheline and other minerals. C) MNKS L10 1115 (RM group 1.1, phonolite) is mostly 
nepheline, analcime, and augite. It also has phillipsite and chabazite, indicating alteration. D) MNKS L10 456 (RM group 2.4, trachyte) is mostly feldspar (both plagioclase and Kfeldspar), with significant augite and Ti-magnetite. E) HWK EE L2 2028 (RM ground 2.6, trachyte) is mostly feldspar (both plagioclase and $\mathrm{K}$-feldspar), with minor Timagnetite. This sample also contains smectite, indicating incipient alteration. F) EF-HR L2 504 (RM group 3.3, basalt) is almost entirely composed of augite and plagioclase.

Figure 6. Example photomicrographs of lava thin sections in plane (PPL) and crossed polarized (XPL) light. Photomicrographs for all thin sections examined are provided in Appendix 3. A and B) HWK EE L2-2028 (trachytic RM group 2.6), in PPL and XPL, 4x mag. Clusters of feldspar phenocrysts in a matrix of finer-grained feldspar with trachytic texture. Feldspar includes both polysynthetic plagioclase and sanidine. C and D) HWK EE L6-994 (basaltic RM group 3.7b), in PPL and XPL, 10x mag. Large, euhedral augite phenocrysts in a matrix of finer augite and plagioclase laths. E and F) EF-HR L1-119 (phonolitic RM group 1.3), in PPL and XPL, 10x mag. Large euhedral to subhedral phenocrysts of both augite (green) and nepheline (white) in a finer-grained matrix. $\mathbf{G}$ and H) HWK EE L2-2870 (basaltic RM group 3.2.1), in PPL and XPL, 4x mag. Vesicular basalt with fine grained matrix of augite and plagioclase.

Figure 7. Example photomicrographs of quartzite thin sections in plane (PPL) and crossed polarized (XPL) light. A and B) NS-S1 (Naibor Soit quartzite), in XPL and PPL, $4 \mathrm{x}$ mag. Coarse grained, interlocking quartz dominates, with minor muscovite both within individual quartz grains and along margins. C and D) SIU-S2 (Naisiusiu quartzite), in XPL and PPL, 4x mag. Medium-grained, interlocking quartz dominates, with small, oriented muscovite laths both within individual quartz grains and along margins. In both samples, original sedimentary grain boundaries and structures are absent.

Figure 8. Relative frequencies of amount and weight of main raw materials in HWK EE (OGAP and Leakey collections together) and EF-HR. A) Number of artifacts per rock type. B) Total weight per rock type. C and D) Weight per raw material sub-groups at HWK EE (C) and EF-HR (D). E-H) Comparison of each raw material sub-group weight. Data from Table $4(\mathrm{~A}-\mathrm{B})$ and Table $5(\mathrm{C}-\mathrm{H})$. T-Ta $=$ trachyte to trachyandesite group.

Figure 9. Breakdown of raw materials per technological group (A-B and D-E) and per texture (C and F). A-C) Amount of stone tools. D-F) total weight. Data from Table 6 (A-B and D-E) and Table 7 (C and F).

Figure 10. Raw materials of artifacts and unmodified lithics in HWK EE (OGAP collection) per general rock types (A and E) and textural features (B-D and F-H). A-D) Amount of stone tools and unmodified pieces. E-H) Total weight per group. Data from Table 8 ( $\mathrm{A}$ and $\mathrm{E}$ ) and Table 10 (B-D and $\mathrm{F}-\mathrm{H})$. $\mathrm{M}-\mathrm{F}=$ medium-fine, $\mathrm{C} / \mathrm{P}=$ coarse/porphyritic, $\mathrm{VC}=$ very coarse, Ves. = vesicular. 


\section{Appendices}

Appendix 1. Photographic atlas of macroscopic raw material groups.

Appendix 2. Thin section point counting results for Olduvai raw material (lava) groups, organized by macroscopic RM group.

Appendix 3. Photographic atlas of volcanic raw materials in thin section. 